\title{
Understanding the different challenges facing students in transitioning to university particularly with a focus on ethnicity
}

\author{
Hannah Parker ${ }^{1}$, Annie Hughes ${ }^{3}$, Caleb Marsh ${ }^{1}$, Sadia Ahmed ${ }^{1}$, James Cannon ${ }^{2}$, Emma \\ Taylor-Steeds ${ }^{3}$, Lucy Jones ${ }^{1}$ \& Nigel Page ${ }^{1, *}$
}

School of Life Sciences, Pharmacy and Chemistry'; Education Liaison and Outreach²; Equality, Diversity and Inclusion Centre ${ }^{3}$; Kingston University London

*Corresponding Author: N.Page@kingston.ac.uk

Keywords: Transition, widening participation, ethnicity

\begin{abstract}
A positive and successful transition into University is crucial if students are to stay the course in higher education and experience successful outcomes. However, challenges exist in ensuring a connected transition from secondary and further education to higher education that is inclusive and supports the diversity in our current undergraduate student body. We set out to explore the diverse experiences that first year students report about their recent transition to a post-1992 University. We were particularly interested in how these experiences and challenges differed by ethnicity. This is incredibly important given the disparity, recognised in the sector, in the attainment of Black and Minority Ethnic (BME) students compared to their White counterparts and particularly pertinent that this trend reverses attainment patterns in secondary education. This paper summarises some of our key findings in determining the challenges facing students from different backgrounds in their transition to university. It argues that Universities will have to change their transition and wider offer to ensure that diverse students feel welcomed and develop a sense belonging in Higher Education in order for them to achieve successful outcomes.
\end{abstract}

\section{Introduction}

There are many academic and non-academic obstacles that students must overcome when transitioning from School/Further Education (FE) to Higher Education (HE). Although the first year of university can be an exciting time for students, it can also be the most challenging in terms of personal adjustment.

A positive and successful transition into University is crucial if students are to stay the course in higher education and experience successful outcomes. However, we know that different groups of students have differential experiences and outcomes based on a number of socio-cultural and economic differences. Central to the purpose of this paper is the growing body of evidence which highlights that students coming from Black and Ethnic Minority backgrounds have less successful outcomes in higher education. HEFCE (2015) reports that the difference between White and BME graduates is 16 percentage point (76 compared to 60 ). This gap reduced by only 1 percentage point when a range of factors were controlled such as age, disability status, subject of study, prior attainment and so on. HESA data (2014/5) from some of our own courses for example in pharmaceutical science and biochemistry indicated lower VA scores $(0.44,0.46$, less than the optimum 1 , where $V A$, represents the 
differences in attainment set against expected targets). Therefore, whilst the attainment gap has decreased from its peak of $18.8 \%$ in 2005/06 (Equality Change Unit, 2014), the gap in attainment remains considerable. This gap in degree performance has become known across the HE sector as the 'BME attainment gap'. The underperformance of Black and Ethnic Minority students in higher education contrasts significantly with academic achievement patterns of pupils in secondary education, where all Black, Minority Ethnic (BME) groups, except for Black boys, outperform White pupils in GCSE attainment (Department for Education, 2016). BME students are also substantially more likely to go to university than their White counterparts (Crawford \& Greaves, 2015). Kingston University has a significant number of BME students (51\% of all students and up to nearly $90 \%$ on some science courses) with many courses having their own distinct ethnic and gender make up.

The question arises about the role of transition into higher education and how different groups of students experience the evolution from school or college to higher education. Simultaneously, questions are raised about the preparedness of universities to ensure that students from diverse backgrounds feel welcomed and are prepared for study in higher education institutions.

Feelings of belonging are fundamental to a positive leaning experience (Read, 2003) and therefore a successful transition (Frame, 2015). Indeed, existing work around the BME attainment gap and differential attainment highlights the importance of students' sense of belonging and the positivity of their daily interactions within their institutions as centrally important in achieving successful outcomes (HEFCE, 2015b). Making friends and encouraging relationships with peers and staff are recognised components of belonging (Read et al. 2003; Thomas, 2012). The implication here is that BME students do not feel the same sense of belonging as their White peers and, more significantly, that Higher Education Institutions are potentially not taking sufficient steps to ensure that their environments are inclusive and that they welcome and encourage BME students to feel that they belong.

The period of transition to university is a key moment where a sense of belonging can be engendered (Thomas, 2012). This project aims to explore the differential experiences and expectations of White students and students coming from Black and Minority Ethnic backgrounds who have just transitioned into higher education in a post-92 London University. It examines their challenges and asks if the University is doing enough to ensure that the transition to university is successful for all students.

\section{Methodology}

An ethically approved (Kingston University Centre for Higher Education Research \& Practice Ethics Panel) paper-based survey was developed that included the fundamental research questions alongside demographic data. The survey was piloted with a small group before being completed by a wider cohort during their classes. This cohort comprised undergraduate students at level 4 ( $1^{\text {st }}$ year) who were studying a range of different courses (including biological sciences, biochemistry, pharmacology, biomedical science, nutrition, pharmaceutical science and pharmacy) within the School of Life Sciences, Pharmacy and Chemistry.

Surveys were anonymous. Numerical data was then extracted and managed using PowerBi pivot tables, where the output was tabulated or displayed graphically.

To support the quantitative findings, two focus groups were organised to generate qualitative data. A total of 12 participants from both BME and White backgrounds participated. Respondents attended for a one hour session. Participants were then asked first to respond to a list of pre-designed questions by writing their thoughts on post-it notes and placing them in the middle of the table. The question was then reiterated and discussed as a group, with the main themes being recorded by a note-taker. At the end of the session, post-it notes were collected with the permission of the participants, and used for later reflection along with the notes taken during the group discussion. 


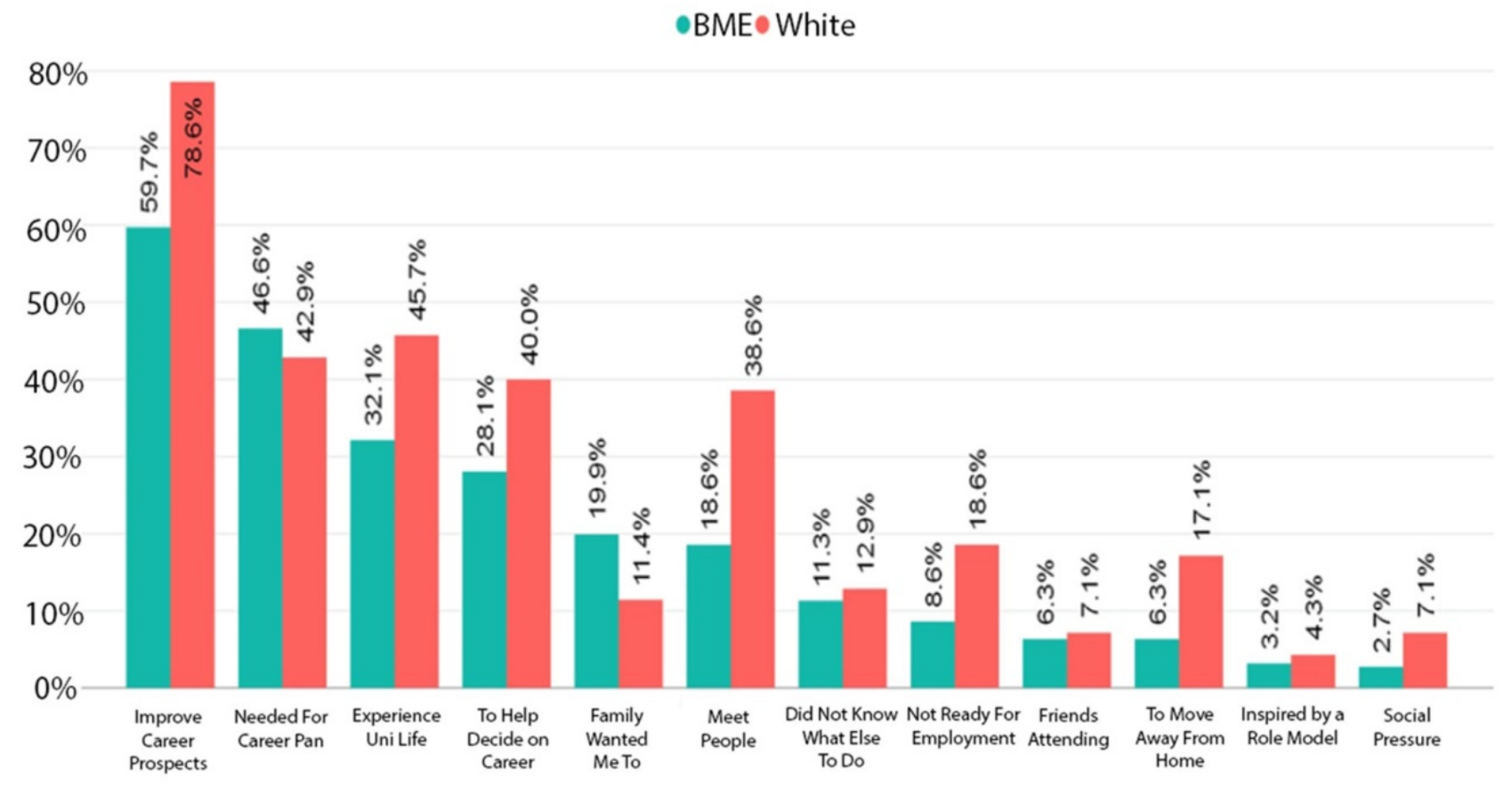

Figure $1 \mathrm{~A}$ comparison of the motivators for deciding to attend university.

\section{Results}

\section{Respondent Characteristics}

A total of 316 undergraduate students completed the survey. Of the collected surveys, 20 were removed owing to the participants having international qualifications. Surveys which did not declare their ethnicity were also removed. The final data set consisted of 289 surveys. $76 \%$ of these students came from BME backgrounds and a further $24 \%$ were recorded as being from White ethnic backgrounds. BME males ( $n=$ $81,28 \%)$ were more prevalent than White males $(n=38,13 \%)$ but overall, female BME students were the most common group $(n=138,48 \%)$ while White females the least $(n=32,11 \%)$. However, the proportion of Chinese, Black Caribbean, Mixed and 'Other' groups are arguably too low to be representative of a population.

\section{Expectations}

Participants were first asked why they decided to attend university (Figure 1). The primary reason given by all students was to improve their career prospects. However, there was a differential in responses, where BME students $(59.7 \%)$ felt less strongly than White students
(78.6\%) that university would indeed improve their career prospects.

Participants were also asked why they chose their degree subject (Figure 2). Most students chose their course out of 'interest or enjoyment' of the topic. However, over half of White students (54.3\%) also believed that their subject choice would be good for a future career plan; significantly fewer BME students $(36.7 \%)$ shared the same opinion. Interestingly, fewer students from Black and Minority Ethnic backgrounds stated that they came to university as a means of 'helping decide on a career', where only $28.1 \%$ of BME students felt this in comparison to $40 \%$ White students.

Differences also showed that BME students (32.1\%) were less likely to come to university to experience university life than their White peers $(45.7 \%)$; and less driven $(18.6 \%)$ to 'meet new people' at university than White students (38.6\%).

Similar numbers of BME and White students chose to take 'advice from family and friends' when deciding on degree subject (Figure 3). 
Understanding the different challenges facing students in transitioning to university particularly with a focus on ethnicity

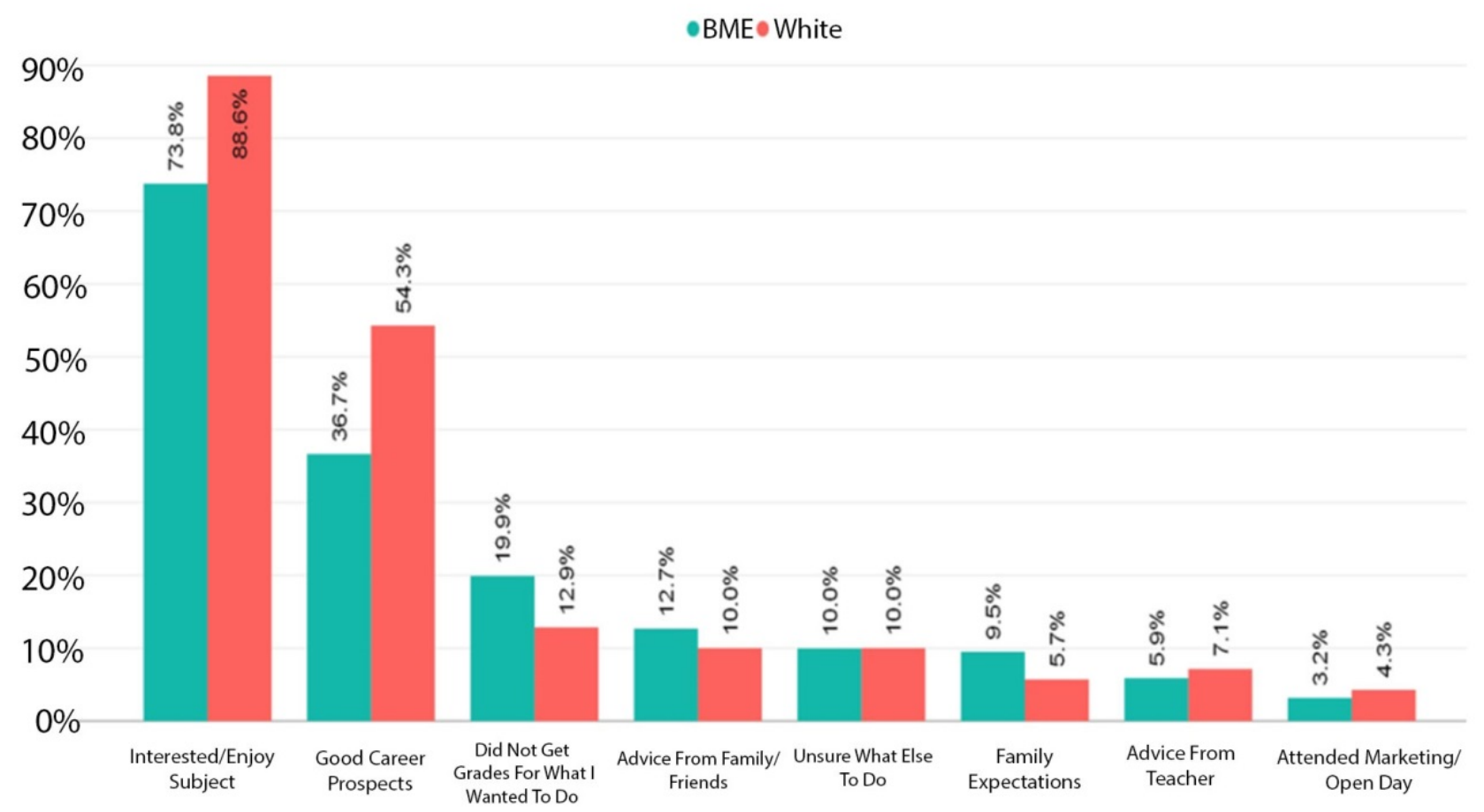

Figure 2 A comparison of the reasons for choosing degree subject.

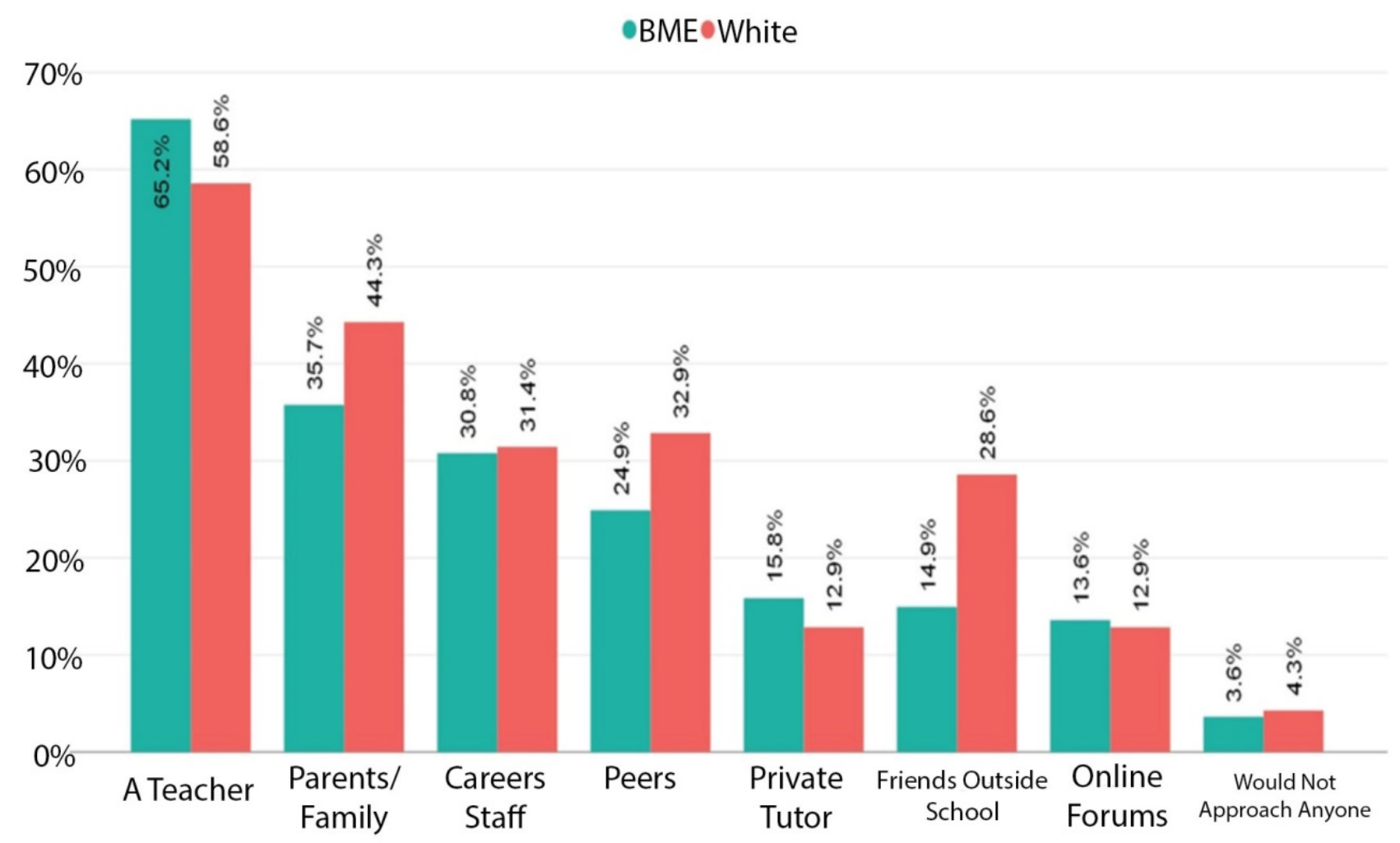

Figure 3 A comparison of where students at school/college would seek advice about attending university 


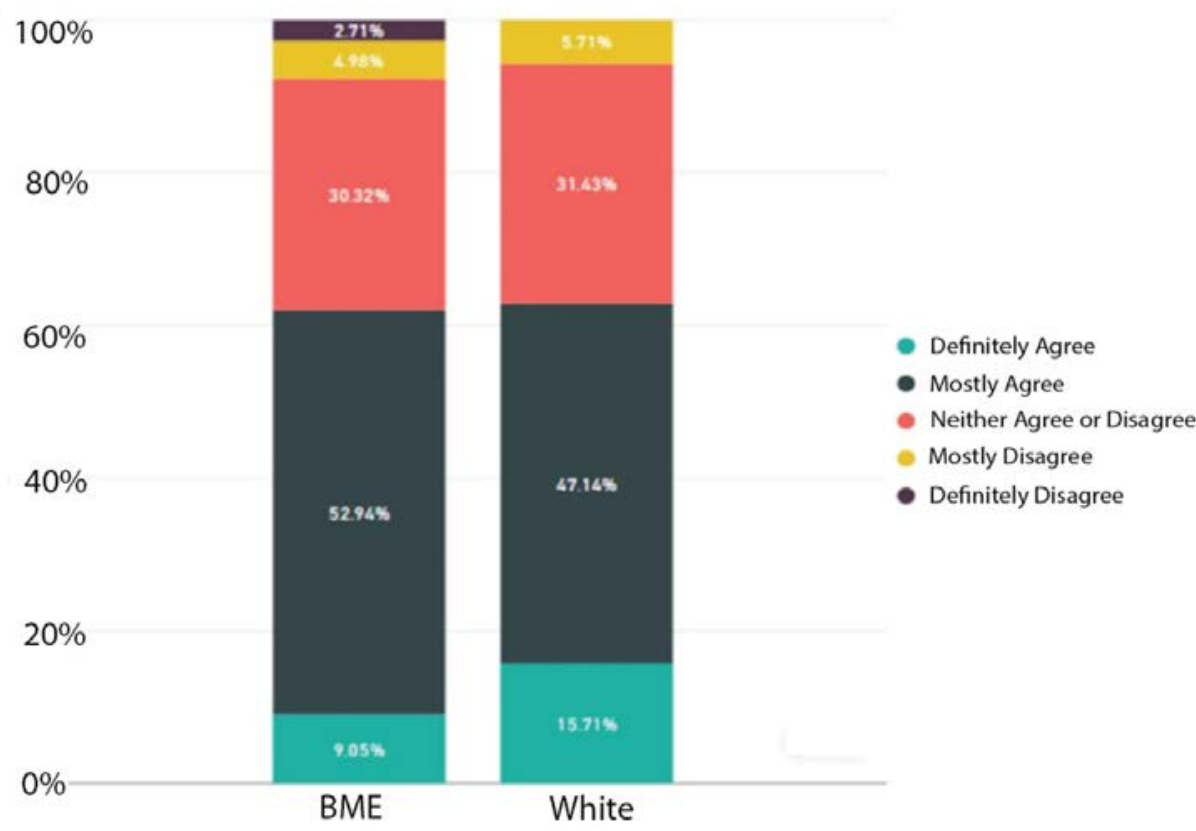

Figure 4 Comparison of expectations at university matching the advice received at school/college.

Existing work has suggested that students who feel that their expectations have not been met are less satisfied and feel more alienated, unwelcome or not part of the community in higher education. To identify if this was a factor, students were asked if they felt their experiences at university matched their expectations based on advice they were given before attending university (Figure 4). Responses from both BME (61.9\%) and White students (62.8\%) suggest that they are both in close agreement: generally their expectations of university are met based on previous advice, although it is interesting to note that White students were slightly more inclined to strongly agree in comparison to BME students.

\section{Belonging}

Inclusion and a sense of belonging are suggested to have an impact on a student's learning experience. Therefore, students were asked if they felt welcome and part of a community when in school or college (Figure 5). To allow for comparison, we also asked if they now felt welcome as part of a university community (Figure 5). More BME students 'definitely agreed' or 'mostly agreed' that they felt welcome in school or college (80\%) than they do now at university (68\%). Interestingly, the trend was reversed for White students, where $72 \%$ 'definitely agreed' or 'mostly agreed' that they felt welcome in their earlier education compared to $82.8 \%$ now feeling welcome and part of a community at university.

Participants where then asked to choose from a list of responses what they felt the university could do to help them succeed in their studies and create a better learning community (Figure 6). BME students were less likely to identify social aspects of university than their White student's counterparts. These included factors such as 'better opportunities to get to know other students' (BME 34.8\%, White $42.9 \%)$, 'having a student society related to their course' (BME 16.7\%, White 21.4\%), 'more student spaces' (BME 31.7\%, White $40 \%)$ and 'more staff-student social events' (BME 14.9\%, White 25.7\%). Conversely, BME students felt that more independent study support was required. For instance, BME students (40.7\%) answered that more 'online courses and activities' would be beneficial in comparison to White students (32.9\%). It was also observed that respondents from Black and Minority Ethnic backgrounds felt that they would benefit from 'one to one progress sessions' (BME 36.2\%, White 30\%) compared to 'more personal tutor meetings' which were less important to BME students (18.1\%), White (32.9\%). 
Understanding the different challenges facing students in transitioning to university particularly with a focus on ethnicity

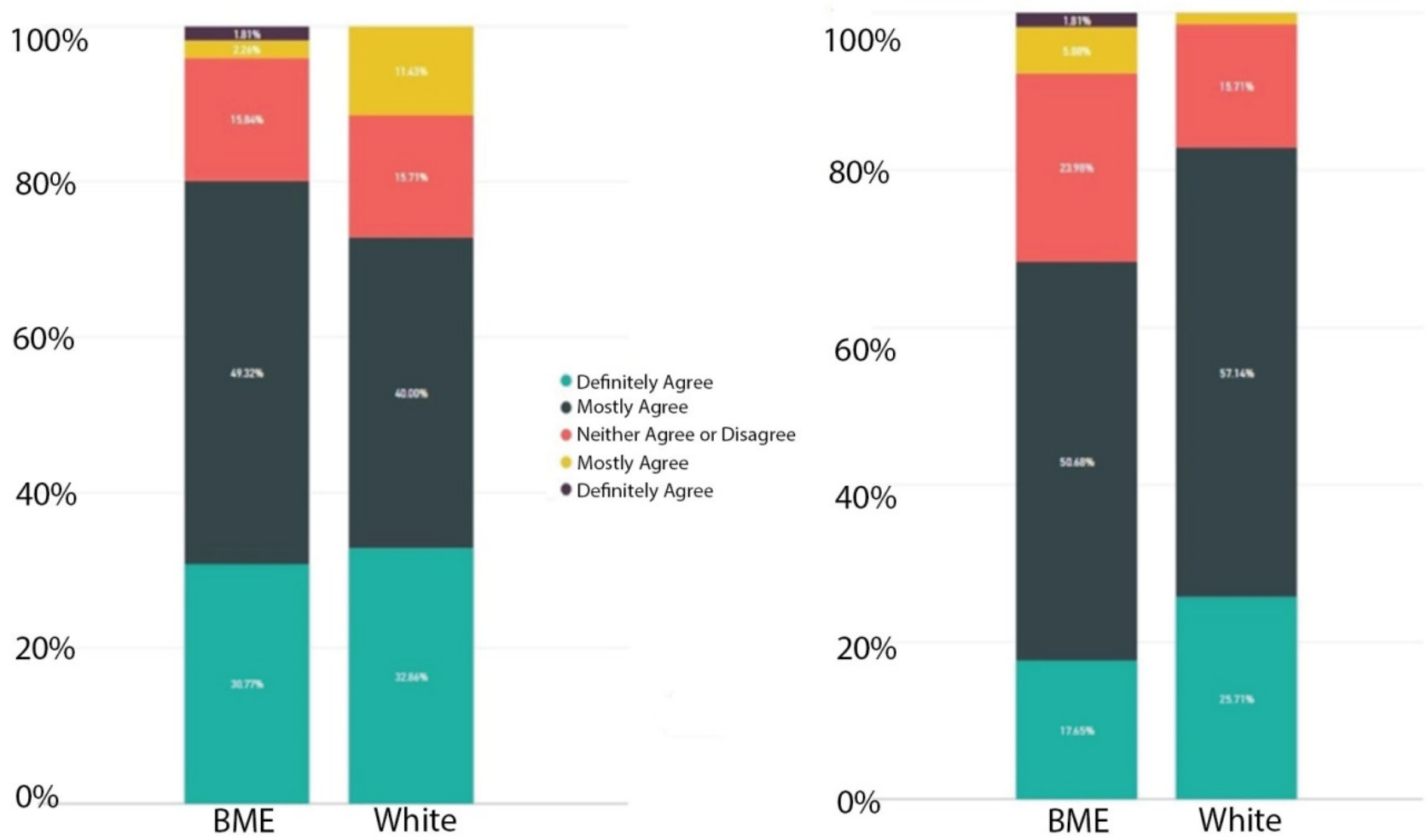

Figure 5 Comparison of feeling welcomed and part of a community at school/college (left panel) and university (right panel).

$\bullet B M E \bullet$ White

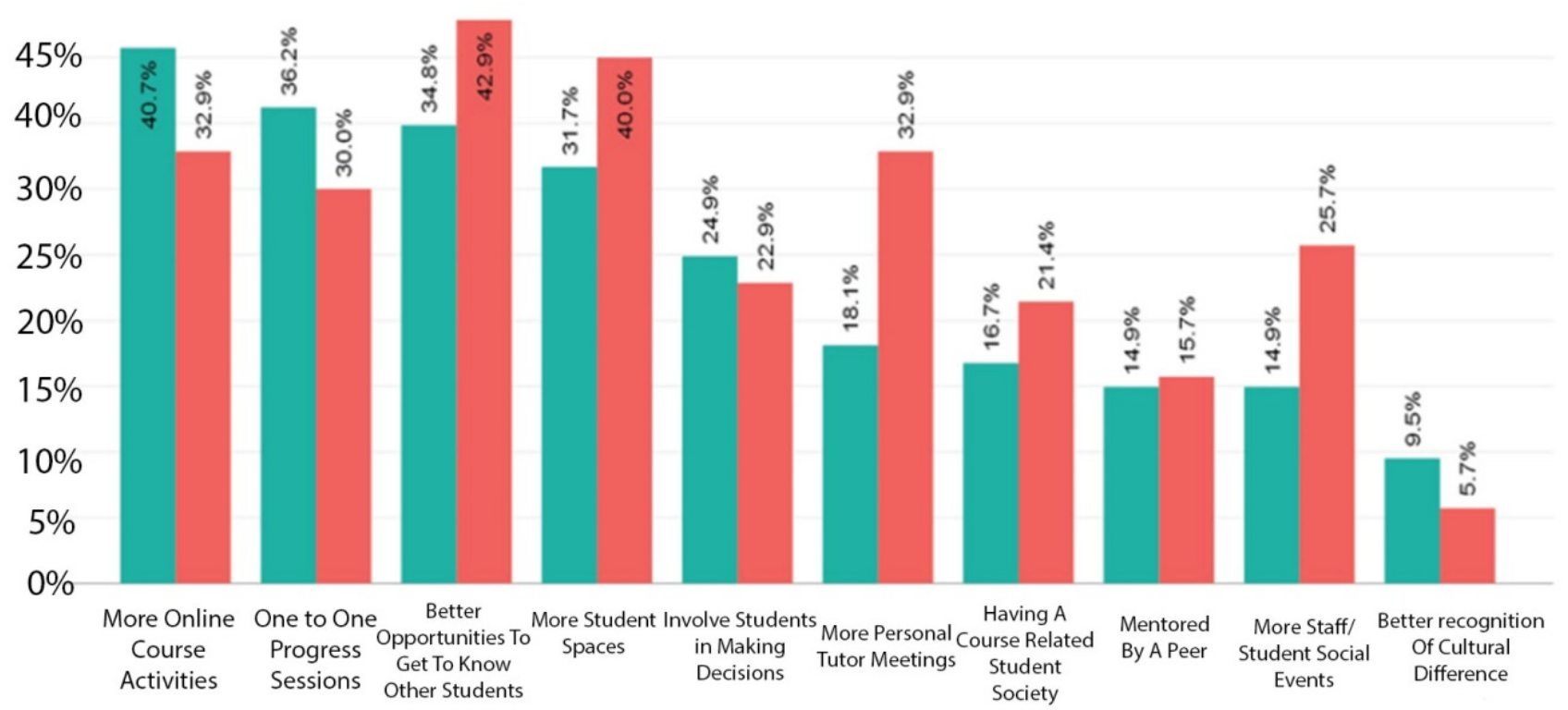

Figure 6 Comparison of what the university could do to help students succeed in their studies and create a better learning community. 
Understanding the different challenges facing students in transitioning to university particularly with a focus on ethnicity

\section{Focus group questions and responses}

\section{What challenges did you face when transitioning to university?}

When asked, what challenges they faced when transitioning from school or college to university a range of issues were raised. The challenges of commuting were discussed at length several times.

"With school you know what you're getting, there is a routine. You get more out of a school day and more contact hours with staff. The commute is much longer than school."

The challenges of social integration for students who did not share a 'traditional student lifestyle' were also identified. For example, students drew attention to the fact that if they did not drink alcohol they were isolated and at a disadvantage when making friends, as many social events and activities involved the consumption of alcohol.

"Halls are a very different environment from home, foundation year helped me integrate and make friends, but I was commuting in then. The shock came when I moved into halls. My parents are very conservative and I just wasn't prepared for some of the stuff. There are so many people here, I'm emotionally and mentally lost sometimes."

"Living in halls is like being in jail sometimes, well it is when you don't drink, I'm isolated and there is nothing to do."

\section{What do you perceive to be a welcoming environment in an academic institution such as school, college and university?}

It was felt that a welcoming environment in an academic institution was created by supportive staff, smaller lecture groups and space to relax so that students could meet new people. It was also noted that students found an understanding of their different backgrounds by interaction with fellow students and the university, making them feel more involved in the learning community.
"There should be an understanding of differences in the student, for example, ethnic background or educational background. Welcome those differences to make us feel welcome don't discriminate."

"Large groups can have 300 students (at one time). It's much harder to make friends in larger groups. People are only familiar faces; you never actually speak to anyone. At school, you know everyone, same at college, your groups are really small and you have known everyone for years."

\section{What could Kingston University do to help students succeed and create an improved, more welcoming learning environment?}

Respondents felt that the University could do more to encourage a sense of belonging. For example, more initiatives which supported commuting students were suggested and would be welcomed such as on-line materials and support. There was also a feeling that the University and its offer should better address the needs of its diverse student body. For example, there was a clear view that Fresher's Fair needed to improve. It was felt that it was only effective as a mechanism for integration and engagement for students who wanted to go 'clubbing'.

Respondents also suggested that they would welcome more study skills sessions such as academic writing and referencing, better communication and the opportunity to meet existing students.

$$
\begin{aligned}
& \text { "It would be good, before you start } \\
& \text { university, when you're in } 6^{\text {th }} \text { form to go to } \\
& \text { the university you have applied to and } \\
& \text { meet } 1^{\text {st }} \text { year students and ask them } \\
& \text { about the challenges" }
\end{aligned}
$$

Was there any beneficial support provided to you by school or college that is not now available at university?

Many of the students perceived school as a more bounded environment where criteria were clearly set and they knew what was expected of them. 
Understanding the different challenges facing students in transitioning to university particularly with a focus on ethnicity

"At uni it's easy to fall into a trap of overthinking work at uni, due to lack of set boundaries."

There was a clear sense that the University made a great number of assumptions about the skills that its new students possessed, which was to the detriment of many of the students.

"Yes, there was more guidance on what you need to know (at school), for example, now at university the only reason I knew how to write a lab report was because of my foundation year, we did none of that at school or college and you're just expected to know how to do it here."

"Loads of skills are missing; l'd never heard of referencing before I came here. Also, my written skills the standard is a huge jump and there needs to be lectures on writing."

\section{Discussion}

The most common reason that students in the survey gave for attending university was that it would improve their career prospects. However, there were significant differences between students. Students from Black and Minority Ethnic backgrounds were less likely to select this as the main reason for attending University compared to their White counterparts. Notwithstanding this, the research suggests there was little difference in the perception of met and unmet expectations between respondents from a BME background compared to those from a White background. Both groups were generally in agreement that their expectations based on pre-entry advice had been met. However, this contradicts narratives which developed from the focus groups, which suggested that students felt unprepared and would have appreciated some engagement with existing first year students prior to their enrolment in order to understand further the social and academic implications of undertaking a degree. Further research into the ways that the university could better inform pre-entry students of the academic and social implications of HE could be a useful tool to aid students in their transition. This is important as students who do not feel that their expectations of university are met are reported to be more likely to withdraw. Indeed, this was the primary reason for withdrawal of first year students in an existing study at this University (May \& Bousted, 2003 cited in Beacock, 2015). Pre-arrival expectations of $\mathrm{HE}$ have been found to influence the success of student transition (Bowles et al., 2011). As the student population becomes more diverse, so do expectations. Universities need to be cognisant of this and cater for it accordingly.

This study suggests that all students felt that the operation of higher education is dramatically different from their school or college and transition was more challenging than they have first thought. There was a clear sense from students from all backgrounds that universities assumed a great deal of knowledge and skill, which a new entrant to higher education did not feel secure in. It was clear that schools and colleges more clearly articulate what they expect from their students and higher education should mirror this.

Importantly, students from Black and Minority Ethnic backgrounds reported that they felt less welcome in their higher education setting, and many felt that they did not feel part of a community at university when compared with their White peers. This was converse to the responses that students gave for their feelings of belonging in their school or college. Further research into initiatives in schools and colleges that form inclusive cultures may help in identifying initiatives in higher education to improve the experiences of BME students as they transition into higher education.

Interestingly, BME students were much less likely to state that 'university life' attracted them to university. This supports existing work that reports that BME students who do live on campus tend to stay in their own friendship groups for socialising, unless wider university social interaction is planned (Cavanagh, 2008; Sims, 2007). This also concurs with the work of Stevenson (2012) who suggests that BME students did not feel that universities did enough to integrate them socially, especially those who did not drink alcohol (see also Singh, 2009). There are clear parallels with the findings of this work where students report 
Understanding the different challenges facing students in transitioning to university particularly with a focus on ethnicity

that they feel alienated due to the drinking culture around many student activities.

It follows then that universities will have to change their transition and wider offer to ensure that diverse students feel welcomed and develop a sense belonging in higher education in order for them to achieve successful outcomes (Thomas, 2012). Whilst important, universities should not simply be relying on student societies to provide spaces where alcohol is avoided.

Cross-cultural interaction at university has been found to support growth in a students' general knowledge, critical thinking, problemsolving skills, and intellectual and social confidence (Chang et al. 2006; Sims, 2007). Universities need to engage more effectively with ensuring that diversity in their student population is translated into inclusion through ensuring that their physical and social spaces, and their curriculum and co-curricular activities, promote interfaith, interracial or inter-class interactions (Cavanagh, 2008).

In summary, our results have highlighted some significant differences in responses between BME and White students in their transitional experiences. Further research into concepts of belonging and isolation of students of different religious and cultural backgrounds may generate further ideas for universities to support the integration of the student community.

\section{References}

Beacock, O., Jackson-Cole, D., May, S., McDuff, N. \& Tatam, J. (2015) Literature review of the BME Attainment Gap at Kingston University and beyond. Available at: http://www. kingston.ac.uk/aboutkingstonunive rsity/equality-diversity-and-inclusion/bmeattainment-gap/

Bowles, A., Dobson, A., Fisher, R. \& McPhail, R. (2011) An exploratory investigation into first year student transition to university. Research and Development in Higher Education, 34, 6171. Available at:

http://www.herdsa.org.au/system/files/HERDS A 2011 Bowles.PDF
Cavanagh, S. (2008) Inclusive Campus: Accommodation and Social Space Guidance 2008. The Equality Change Unit, ECU Publications, London. Available at: http://www.ecu.ac.uk/wp-

content/uploads/external/inclusive-campus.pdf

Chang, J., Denson, N., Saenz, V. \& Misa, K. (2006) The Educational Benefits of Sustaining Cross-Racial Interaction among Undergraduates. The Journal of Higher Education, 77, 430-455. DOI: 10.1353/jhe.2006.0018

Crawford, C. \& Greaves, E. (2015) Ethnic minorities substantially more likely to go to university than their White British peers. Institute for Fiscal Studies. Available at: https://www.ifs.org.uk/publications/8042

Department for Education (2016) Revised GCSE and equivalent results in England, 2014 to 2015. Department for Education Available at:

https://www.gov.uk/government/uploads/syste m/uploads/attachment data/file/494073/SFR0 1 2016.pdf

Equality Change Unit (2015) Equality in Higher Education: Statistical Report 2015 Part 2: students. Available at:

http://www.ecu.ac.uk/wpcontent/uploads/2015/11/Equality-in-HEstatistical-report-2015-part-2-students.pdf

Equality Change Unit (2014) Equality in Higher Education: Statistical report 2014 Part 2: students. Available at:

http://www.ecu.ac.uk/wpcontent/uploads/2014/11/ECU HE-statsreport student v19.pdf

Frame, M. (2015) Building belonging with the curriculum: Optimum combinations of pedagogies for Level 1 students. The Higher Education Academy. Available at: https://www.heacademy.ac.uk/knowledgehub/building-belonging-curriculum-optimumcombinations-pedagogies-level-1-students 
HEFCE (2015) Differences in degree outcomes: The effect of subject and student characteristics. Available at:

http://www.hefce.ac.uk/media/HEFCE,2014/C ontent/Pubs/2015/201521/HEFCE2015 21.pd f

HEFCE (2015b) Causes of differences in student outcomes. Available at:

http://www.hefce.ac.uk/media/HEFCE,2014/C ontent/Pubs/Independentresearch/2015/Caus es,of,differences,in,student,outcomes/HEFCE 2015 diffout.pdf

Read, B., Archer, L. \& Leathwood, C. (2003) Challenging Cultures? Student Conceptions of 'Belonging' and 'Isolation' at a Post-1992 University. Studies in Higher Education, 28, 262-277. DOI: 10.1080/03075070309290

Sims, J. (2009) Not Enough Understanding? Student Experiences of Diversity in UK Universities. A Runnymede Community Study. United Kingdom. Available at: https://www.runnymedetrust.org/uploads/publi cations/pdfs/NotEnoughUnderstanding2007.pdf

Singh, G. (2009) Black and Minority Ethnic (BME) students' participation in higher education: improving retention and success. EvidenceNet, Higher Education Academy. Available at:

https://www.heacademy.ac.uk/system/files/bm e synthesis final.pdf

Stevenson, J. (2012) Black Minority Ethnic Student Degree Retention and Attainment. Higher Education Academy. United Kingdom. Available at:

https://www.heacademy.ac.uk/system/files/bm e summit final report.pdf

Thomas, L. (2012) What Works - Student Retention and Success. Higher Education Academy. United Kingdom. Available at: https://www.heacademy.ac.uk/wasrsprogramme/what-works-student-retentionand-success
Thomas, L. \& Jones, R. (2007) Embedding employability in the context of widening participation. Learning and employability, Series two. Available at: http://www.employability.ed.ac.uk/documents/ Staff/HEABriefings/ESECT-6WideningParticipation.pdf 